\title{
Sleeve-Type Expansion Anchor Behavior in Cracked and Uncracked Concrete
}

\author{
Sang-Yun Kim ${ }^{1)}$, Sang-Kook Lee ${ }^{1)}$, Sung-Kyu Lee ${ }^{1)}$, Hun-Woo Kwon ${ }^{2)}$, Hae-Suck Lee ${ }^{3)}$, Moon-Hee Yang ${ }^{4)}$ \\ 1) Korea Institute of Nuclear Safety, Taejon, Republic of Korea \\ 2) Korea Electric Power Corporation, Seoul, Republic of Korea \\ 3) Korea Power Engineering Company, Yongin/Kyunggi-Do, Republic of Korea \\ 4) Hilti-Korea, Yongin/Kyunggi-Do, Republic of Korea
}

\begin{abstract}
A test was performed to investigate the effect of concrete cracks on the static behavior of sleeve-type expansion anchors, and to confirm the seismic and fatigue resistance capability in cracked concrete. The tensile and shear test was conducted on single anchors with three sizes. Concrete test specimens are sufficiently large to prevent the effect of the concrete edges on the anchor behavior. The types of failure, the static strength and displacement behavior of the anchors in uncracked and cracked concrete were compared to evaluate the effect of the cracks. The strength reduction rate of the anchors due to the cracks was exhibited almost less than the corresponding value specified in ACI 349, APP. B, Draft. Through the residual strength tests, the seismic and fatigue resistance capability of the anchors was confirmed in cracked concrete. The characteristics of the anchor shear capacity significantly vary with how the displacement failure criteria are determined.
\end{abstract}

\section{INTRODUCTION}

Expansion anchors are widely used in piping and equipment supports in nuclear power plant. The cracks could be generated on concrete members such as slabs and walls that are used mainly to fix the components on, due to not only the concrete shrinkage and temperature variation but also the mechanical loads such as seismic force. Therefore, the performance of the anchor to be installed in nuclear power plant should be qualified in cracked concrete. This paper shows the static behavior, and the seismic and fatigue resistance capability of sleeve-type expansion anchors in cracked concrete. Especially, using three kinds of displacement failure criteria, the characteristics of the anchor shear capacity were compared each other. This was done considering that there are many electrical equipments in nuclear power plant susceptible to the small anchorage displacement.

\section{TEST PROGRAM}

\section{Test Specimens}

Testing was conducted on the sleeve-type expansion anchors, M10, M16 and M24, which have $10 \mathrm{~mm}, 16 \mathrm{~mm}$ and 24 $\mathrm{mm}$ anchor bolt diameter and $75 \mathrm{~mm}, 105 \mathrm{~mm}$ and $155 \mathrm{~mm}$ effective embedment depth respectively. (Fig. 1)

The target concrete compressive strength was $315 \mathrm{~kg} / \mathrm{cm}^{2}(4500 \mathrm{psi})$ at 91 days. The concrete specimens were reinforced with rebar to control the cracks in specific size, but not to affect the concrete breakout failure cone. The dimensions of concrete specimens were $1400 \mathrm{~mm} \times 1400 \mathrm{~mm} \times 300(250) \mathrm{mm}$, and the anchors were installed far from the concrete edges to preclude the edge effects. Test population was decided according to ACI 355.2, Draft [1] and ASTM E488 [2] as shown in Table 1.

\section{Crack Inducement and Anchor Installation}

The anchor holes were drilled with electro-pneumatic drilling machine and carbide tipped drill bit of the specified nominal diameter. The initial crack (about $0.1 \mathrm{~mm}$ ) was induced by insertion of splitting tubes in the pre-drilled holes and tapping them as shown in Fig. 2. Anchors were installed with a maximum deviation of $6^{\circ}$ from the perpendicular in the initially cracked concrete block and tightened to the installation torque. These values were $50 \mathrm{Nm}, 200 \mathrm{Nm}$ and $500 \mathrm{Nm}$ for M10, M16 and M24 anchor respectively. The installed anchors were loosened to $50 \%$ of the installation torque to account for relaxation. The initial crack was widened to $0.5 \mathrm{~mm}$ for the seismic test and $0.3 \mathrm{~mm}$ for the fatigue test by tapping the splitting tube, and the crack width was measured with microscope video at 2 places, which are $30 \mathrm{~mm}$ away from both sides of loading plate. The anchor hole size in the loading plate is the anchor diameter plus $1.6 \mathrm{~mm}$, and the contact surface between the loading plate and the concrete block was not coated for the shear and slip resistance test.

\section{Test Loads}

Test loads were determined in accordance with the specifications of ACI 355.2, Draft and ASTM E488.

The anchors for the static test were loaded to failure and the mean value (Fm) of the ultimate failure loads were used as the base of the seismic and fatigue test input as shown in the Table 2.

According to ACI 355.2, Draft, the test loads for the seismic tension and shear were determined as shown in Fig. 3 and 4, and the loading frequency was $0.1 \sim 2 \mathrm{~Hz}$. Since ACI 355.2, Draft is the test specification of the anchors related to the ACI 318 , APP. D, Draft [3], which is not for the nuclear facilities, ACI 355.2, Draft is for the industrial facilities. USNRC SRP [4] 
subsection 3.7 .2 requires that ten loading cycles per one seismic event shall be considered and five OBEs and one SSE shall be considered per each seismic event. Accordingly, minimum 60 cycles could be applied for the seismic test of anchors used in nuclear power plants. 100 cycles of $0.25 \mathrm{Fm}$ load amplitude used in this test must be enough, and $0.25 \mathrm{Fm}$ can be used for the seismic design level in nuclear power plants. The mean value of failure load, Fm, was determined based on the maximum capacity in tension, and the displacement ( 0.25 anchor diameter) based capacity in shear. (Table 2)

The fatigue tension and shear loads are shown in Fig. 5 and 6 , and have $7-9 \mathrm{~Hz}$ frequency. The mean value of failure load was same with that used in the seismic test input.

For all dynamic tests, pulsating loads in tension and alternating loads in shear were applied.

\section{Test Method}

The test setup for the tension and shear is shown in Fig. 7 and 8 . The concrete blocks for the tensile test were attached to the reaction wall in the testing facility by four high strength bolts. All tests were performed in accordance with ACI 355.2 , Draft and ASTM E488.

The static test was lasted until the failure occurred. For the shear test, the anchors were installed in the hole of the loading plate to allow the displacement in the loading direction, which is same with the direction of the crack. The loading pattern of the seismic and fatigue described above was applied. After the completion of cyclic loading, a static tensile test to failure was performed to verify the residual strength. The ACI 355.2, Draft requires that the residual strength shall not be less than $80 \%$ of the mean capacity obtained through the static test. The crack width was controlled to $0.5 \mathrm{~mm}$ for the static and seismic test according to ACI 355.2, Draft and $0.3 \mathrm{~mm}$ for the fatigue test considering that the fatigue loading takes place in normal condition.

The compressive strength of concrete was designed for $315 \mathrm{~kg} / \mathrm{cm}^{2}$ at 91 days after casting. To verify the concrete strength, the concrete cylinder specimens were made and tested in accordance with ASTM C39. The magnitude of the loads was measured by load cell, which is installed between loading plate and actuator, and the displacement was measured from the head of the anchor bolt to the pre-assigned base point.

For the slip load resistance test, the anchors were loaded with a monotonically increasing shear load at a rate not exceeding $0.076 \mathrm{~mm}(0.003 \mathrm{in}$.) displacement per minute. The test was terminated when the displacement of I.27 mm $(0.05$ in.) was recorded, and the slip resistance load was determined at this point. This slip load resistance test was performed in cracked concrete to consider the preload loss due to the widened cracks.

\section{ANALYSIS OF TEST RESULTS}

\section{Failure Mode of Anchor and Characteristic of Load-Displacement Curve}

All single anchors showed the pullout failure modes in tension independent of the presence of cracks or the effective depths of anchor. M16 and M24 anchors showed the concrete pryout failure modes in shear with no relation to the presence of cracks. (Fig. 9) However, M10 anchors were of steel failures in shear in uncracked concrete, while 4 bolt steel failures and 1 concrete pryout failure of 5 specimens were occurred in cracked concrete. (Fig. 10) This showed the fact that M10 anchors could produce two kinds of shear failure modes in cracked concrete.

The analysis of the load versus displacement curve obtained from the ultimate strength test showed that the displacement of the anchor in cracked concrete elements increased but the strength decreased.

\section{Effect of Concrete Cracks on Static Capacity of Anchor}

\section{Tensile Strength}

Compared to the corresponding value in uncracked concrete, the maximum tensile capacity under the static loading in cracked concrete decreased by $25 \%$ in M10 anchor, 14\% in M16 anchor and 9\% in M24 anchor. (Fig. 11) These decreases are less than reduction value, about $29 \%$, to account for cracks specified in ACI 349, APP. B, Draft. [5]

The effect of cracks on the decrease rate of the anchor strength is proportional to the decrease of the anchor size. The smaller anchor was affected more by cracks, because the failure modes of M10, M16 and M24 anchor were same as pullout, and the widths of cracks generated at the anchor locations were similar.

The displacement at ultimate strength is less than $6 \mathrm{~mm}$, and the displacement behavior was unaffected by cracks.

\section{Shear Strength}

M10 anchors with steel failure modes showed the shear strength in cracked concrete up to $16 \%$ less than the value in uncracked concrete. (Fig. 12) The displacement at ultimate strength of M10 anchor was increased by $15 \%$ due to the crack. This increase of the displacement made the anchor bolt bend more, which seems to decrease the bolt shear capacity. ACI 349 , APP. B, Draft gives no explicit consideration of the effects of cracks on the shear strength of the bolt steel. Therefore, additional study is needed on this issue.

M16 and M24 anchors in cracked concrete showed concrete pryout failure modes. The maximum shear capacity in cracked concrete decreased by $9 \%$ in M16 anchor and 7\% in M24 anchor. (Fig. 12) These decrease rates are less than one third of the reduction value to account for cracks in ACI 349, APP. B, Draft. There are no significant differences of the shear 
capacity reduction rate between M16 and M24 anchor.

\section{Effect of Concrete Cracks on Displacement Based Shear Capacity}

The shear capacity was evaluated using the displacement based capacity concept, and the results are as follows.

In case that $1 / 4 \Phi(\Phi$ :anchor diameter) is selected as displacement failure criteria, the anchor strength decreases to $41 \%$ of the ultimate strength in MI0 anchor, 56\% in M16 anchor and 66\% in M24 anchor in uncracked concrete, and 33\% in M10 anchor, 44\% in M16 anchor and 57\% in M24 anchor in cracked concrete.

As a result of analyzing the effects of cracks on $1 / 4 \Phi$ displacement based strength, it was found that the anchor strength decreased by 33\% in M10 anchor, 28\% in M16 anchor and 19\% in M24 anchor. These rates of the strength reduction are more than twice of the corresponding values obtained with the ultimate strength. The strength reduction rate of the anchor was increased with the decrease of the anchor size. The smaller anchor was affected by cracks more than the larger one.

In case of adopting $6.35 \mathrm{~mm}(1 / 4 \mathrm{in}$.) as an displacement failure criterion, the anchor strength decreases to $62 \%$ of the ultimate strength in M10 anchor, 67\% in M16 anchor and 66\% in M24 anchor in uncracked concrete, and 59\% in M10 anchor, $59 \%$ in M16 anchor and 57\% in M24 anchor in cracked concrete. Compared to the corresponding values in 1/4Ф displacement based strength, the shear strength increases more than $20 \%$ in maximum.

The analysis of the effect of cracks on $6.35 \mathrm{~mm}$ displacement based strength shows that the anchor strength decreases by $20 \%$ in M10 and M16 anchor, 19\% in M 24 anchor. Compared to the corresponding effect on 1/4 $\Phi$ displacement based strength, the effect of cracks on the reduction of the anchor capacity is small. The rates of the strength reduction are similar independent of the size of the anchor. This fact is contrary to the results from $1 / 4 \Phi$ displacement based strength.

In case that $12.7 \mathrm{~mm}(1 / 2 \mathrm{in}$.) is selected as an displacement failure criterion, the anchor strength decreases to $79 \%, 79 \%$ and $83 \%$ of the ultimate strength in M10, M16 and M24 anchor respectively in uncracked concrete, and $75 \%, 76 \%$ and $81 \%$ of the ultimate strength in M10, M16 and M24 anchor respectively in cracked concrete.

After analyzing the effects of cracks on $12.7 \mathrm{~mm}$ displacement based strength, it was found that the anchor strength decreased by $20 \%, 13 \%$ and $10 \%$ in M10, M16 and M24 anchor respectively. The anchor capacity reduction caused by cracks tends to decrease with the increase of the anchor size.

As described above, the anchor shear capacity varies with how the displacement failure criteria are determined. (Fig. 13) The evaluation results are summarized as follows.

Firstly, $12.7 \mathrm{~mm}$ displacement based shear strength of the anchor reaches about $80 \%$ of the ultimate strength independent of the presence of the cracks and the size of the anchor. The anchor capacity reduces abruptly with the decrease of the amount of the displacement as failure criteria.

Secondly, in case of adopting $1 / 4 \Phi, 6.35 \mathrm{~mm}$, and $12.7 \mathrm{~mm}$ as displacement failure criteria, the effect of the crack on the shear strength reduction is less than $30 \%$ except $1 / 4 \Phi$ displacement based strength of M10 anchor, which shows $33 \%$ strength reduction. The larger the displacement as a failure criterion is, the smaller the effect of the crack on the anchor strength reduction is. There are no specific requirements for determining the shear capacity of the anchor based on the displacement failure criteria, and how to consider the anchor capacity reduction due to the cracks in this case.

\section{Seismic Resistance Capability of Anchor in Cracked Concrete}

\section{Tensile Strength}

The residual strength of anchors after seismic test was found to be a little greater than the ultimate strength obtained through the static test with no pre-seismic test, and the displacement at the maximum residual strength was changed little compared with the corresponding value in the static test. (Fig. 14) As a result, it can be seen that the seismic load has little influence on the resisting capacity of the anchors, and the maximum displacement occurred less than $1 \mathrm{~mm}$ even with seismic load.

\section{Shear Strength}

The residual strength of anchors after seismic test was as large as the ultimate strength in the static test. (Fig. 15) The displacement of M10 anchors at the maximum residual strength increased, which exhibited steel failure modes. M16 and M24 anchors showed concrete pryout failure modes. The maximum displacement under seismic load was found less than $6 \mathrm{~mm}$ and the anchors were confirmed to survive successfully under the alternating seismic loads.

\section{Fatigue Resistance Capability of Anchor in Cracked Concrete}

\section{Tensile Strength}

The residual strength after fatigue test exceeded the ultimate strength obtained through the static test. (Fig. 16) The displacement at the maximum residual strength showed little difference from the corresponding value in the static test. The reasons why the residual strength after fatigue test exceeded the ultimate strength in the static test can be assumed as follows. The expanded crack width $(0.3 \mathrm{~mm})$ in the fatigue test is less than that $(0.5 \mathrm{~mm})$ in the static test. Furthermore, the anchoring force of sleeve part was increased under the fatigue loads. 


\section{Shear Strength}

The maximum residual strength after fatigue test exceeded the ultimate strength obtained through the static test. (Fig. 17) The strength of M24 anchor increased by $18 \%$ and the displacement increased relatively large. Considering that the width of expanded cracks used for three specimens are of little difference, the crack width is not believed to be the key parameter for the displacement increase.

Two M10 anchors tested in concrete specimen with similar crack width showed the strength difference of $11 \%$ in steel failure mode.

Through the shear fatigue load test on M10, M16 and M24 anchors, it was found that appropriate magnitude of alternating loads could increase the maximum strength of anchors. This strength increase seems to attribute to enhancement of anchoring force of the sleeve during the tests.

The residual strength was larger than the static shear strength so that the fatigue load tended to increase the shear strength of anchors even when the residual strength was decided on the displacement based strength except $1 / 4 \Phi$ displacement based strength of M10 anchor. (Fig. 18) Consequently, whether based on the ultimate strength of anchors or the displacement based strength, the resisting shear capacity of anchors after fatigue test increased a little.

\section{CONCLUSIONS AND RECOMMENDATIONS}

A test was performed to investigate the effect of concrete cracks on the static behavior of the sleeve-type expansion anchors, and to confirm the seismic and fatigue resistance capability in cracked concrete. The following conclusions and recommendations were drawn from the evaluation of test results.

Firstly, the effect of concrete cracks on the capacity reduction of single anchor are mostly below $25 \%$, which is less than the reduction value to account for cracks specified in ACI 349, APP. B, Draft.

Secondly, even though bolt steel shear failure was occurred in MIO anchor, there was some decrease of shear strength due to the increase of bolt bending caused by the crack. In case of steel failure, shear capacity reduction to account for the cracks is not considered in ACI 349, APP. B, Draft. Additional study is recommended on this issue.

Thirdly, the characteristics of the anchor shear capacity significantly vary with how the displacement failure criteria are determined. The anchor capacity reduces abruptly with the decrease of the amount of the displacement as failure criteria. The larger the displacement as a failure criterion is, the smaller the effect of the cracks on the anchor strength reduction is. The requirements for determining the shear capacity of the anchor based on the displacement failure criteria are necessary in $\mathrm{ACI}$ 349, APP. B, Draft.

Fourthly, the seismic and fatigue resistance capacity of sleeve-type expansion anchor in cracked concrete was confirmed under the alternating in shear and the pulsating in tension. Some level of fatigue load tends to increase the anchor strength by building the anchoring force additionally inside hole in concrete.

\section{REFERENCES}

1. ACI 355.2, Draft, Provisional Test Method for Evaluating the Performance of Post-Installed Mechanical Anchors in Concrete, 09/28/99

2. ASTM E488-96, Standard Test Methods for Strength of Anchors in Concrete and Masonry Elements

3. ACI 318, Appendix D, Draft, Fastenings to Concrete 12/10/98

4. NUREG-0800, Standard Review Plan for the Review of Safety Analysis Reports for Nuclear Power Plants, July 1981

5. ACI 349, Appendix B, Draft, Fastenings in Concrete 06/16/99

6. CEB, Fastenings to Concrete and Masonry Structures, 1994

7. CEB, Design of Fastenings in Concrete, 10/14/98 
Table 1 Test Number

\begin{tabular}{|c|c|c|c|c|c|c|c|c|c|}
\hline \multirow{4}{*}{$\begin{array}{c}\text { Anchor } \\
\text { Dia. } \\
\text { (mm) }\end{array}$} & \multicolumn{9}{|c|}{ Test Number } \\
\hline & \multicolumn{4}{|c|}{ Static Test } & \multicolumn{2}{|c|}{ Seismic Test } & SLRT * & \multicolumn{2}{|c|}{ Fatigue Test } \\
\hline & \multicolumn{2}{|c|}{ Tension } & \multicolumn{2}{|c|}{ Shear } & Tension & Shear & Shear & Tension & Shear \\
\hline & Cracked & Uncracked & Cracked & Uncracked & Cracked & Cracked & Cracked & Cracked & Cracked \\
\hline 10 & 5 & 5 & 5 & 5 & 5 & 5 & 3 & 3 & 3 \\
\hline 16 & 5 & 5 & 5 & 5 & 5 & 5 & 3 & 3 & 3 \\
\hline \multirow[t]{2}{*}{24} & 5 & 5 & 5 & 5 & 5 & 5 & 3 & 3 & 3 \\
\hline & \multicolumn{6}{|c|}{ ACI 355.2} & - & \multicolumn{2}{|c|}{ ASTM E-488 } \\
\hline
\end{tabular}

* SLRT : Slip Load Resistance Test

Table 2 Fm Value for Seismic and Fatigue Test Input

\begin{tabular}{|c|c|c|}
\hline Anchor & $\mathrm{Fm}^{(1)}$ in Tensile Test(KN) & $\mathrm{Fm}^{(2)}$ in Shear Test(KN) \\
\hline M10 & 36 & 22 \\
\hline M16 & 80 & 77 \\
\hline M24 & 133 & 163 \\
\hline
\end{tabular}

(1) Fm : mean value of static ultimate strength

(2) Fm : mean value of displacement(1/4 $\Phi)$ based strength

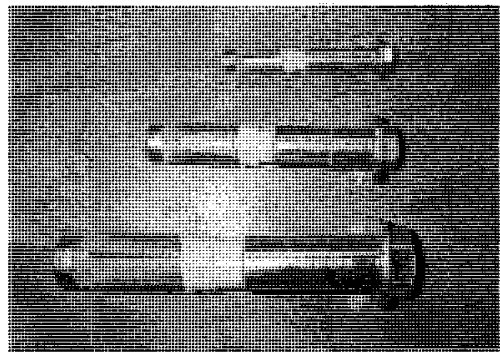

Figire 1 Sleeve-Type Expansion Anchor
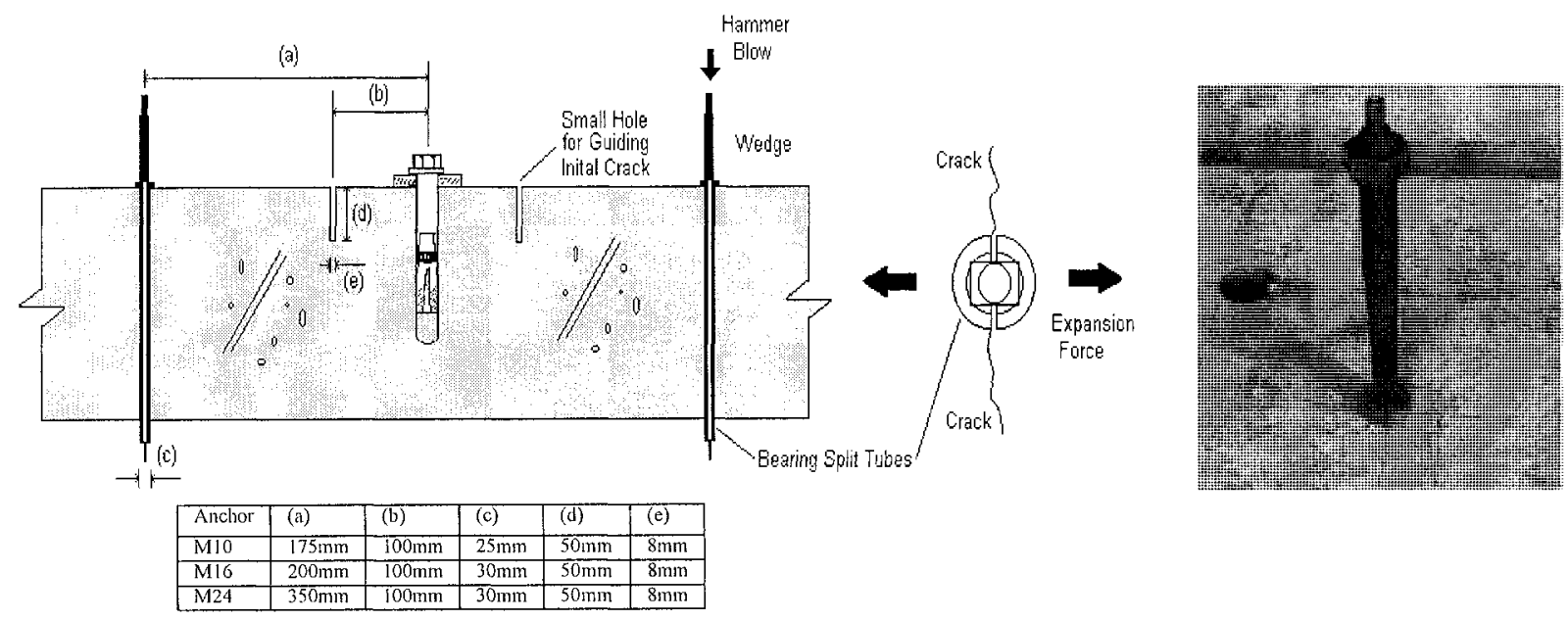

Figire 2 Crack Inducement 


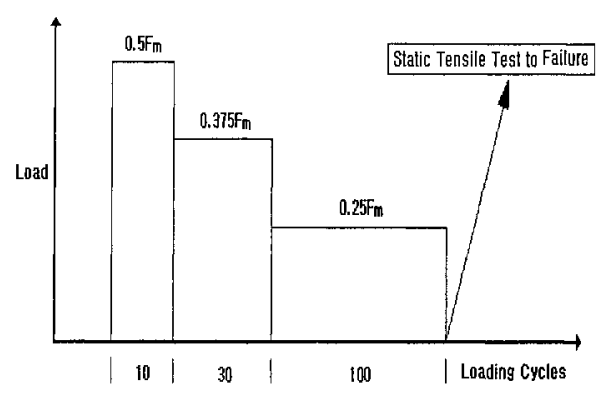

Figure 3 Seismic Tensile Test Input

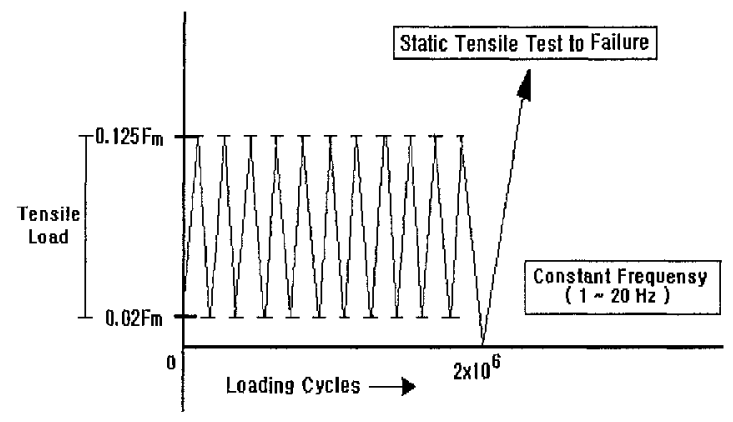

Figure 5 Fatigue Tensile Test Input

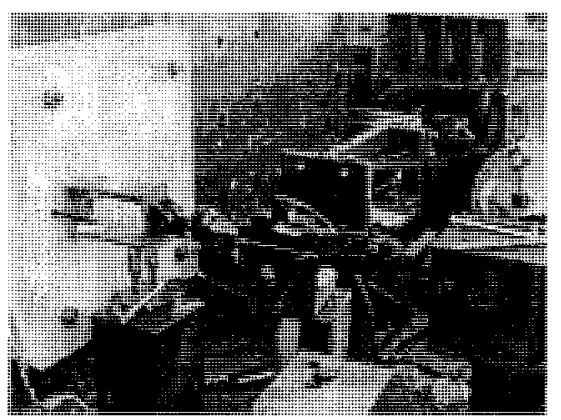

Figure 7 Tensile Test Setup

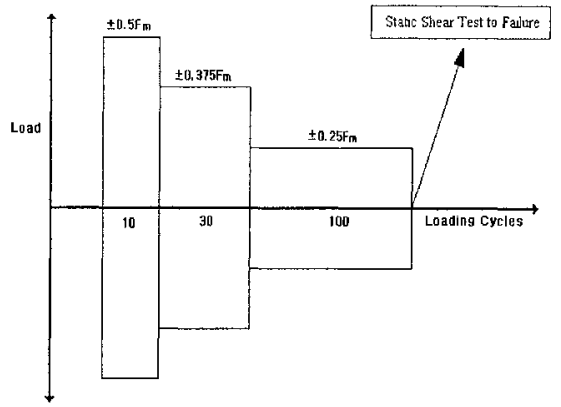

Figure 4 Seismic Shear Test Input

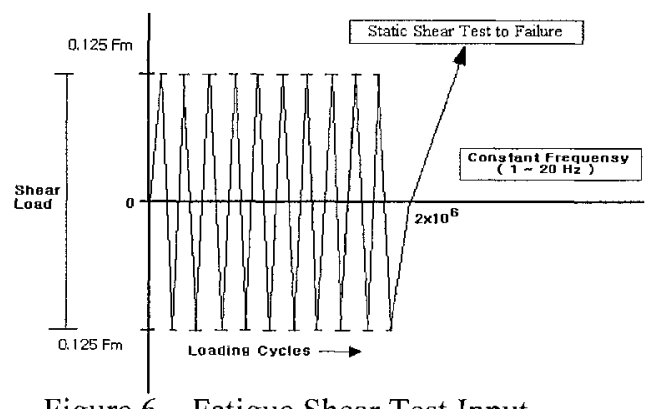

Figure 6 Fatigue Shear Test Input

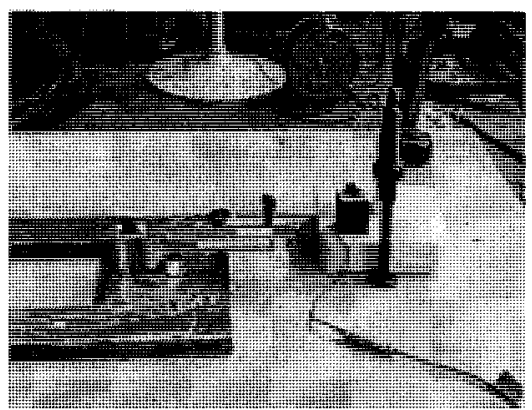

Figure 8 Shear Test Setup
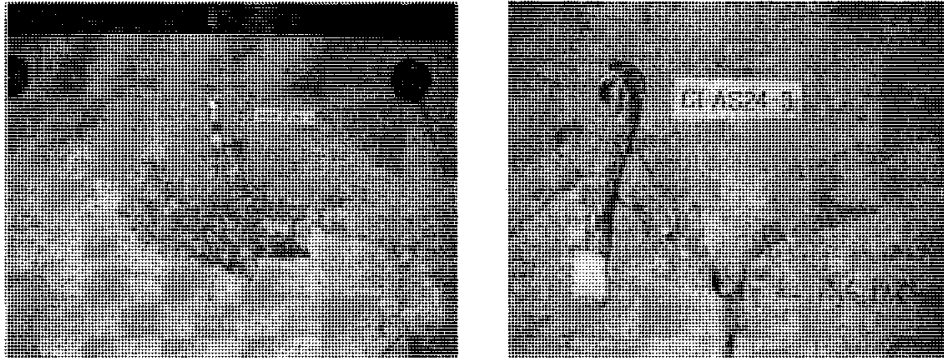

Figure 9 Concrete Pryout Shear Failure

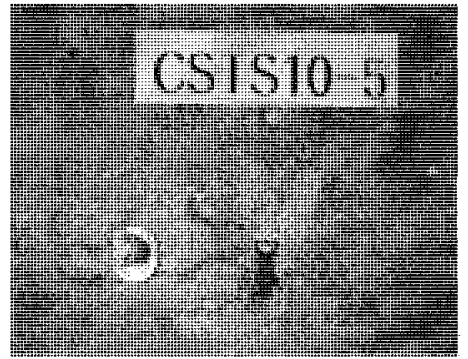

Figure 10 Bolt Steel Shear Failure 


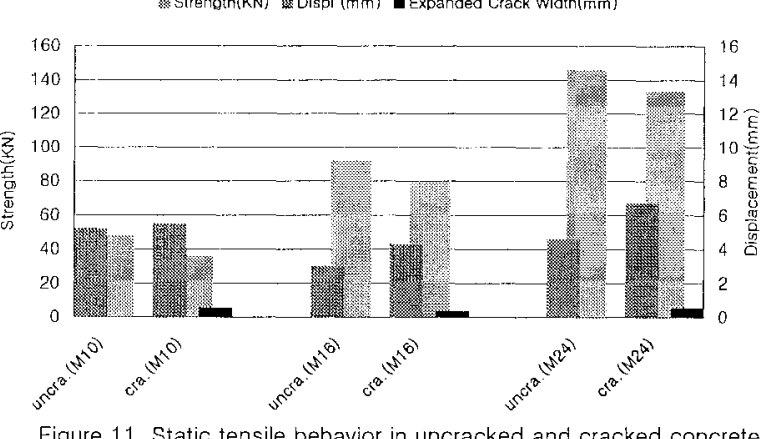

Figure 11 Static tensile behavior in uncracked and cracked concrete

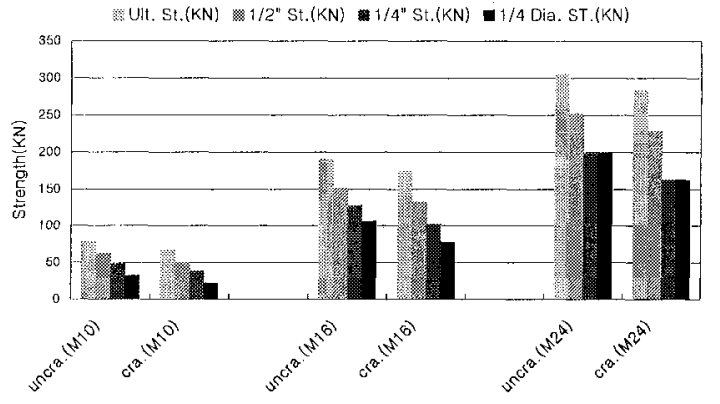

Figure 13 Displacement based shear strength in uncracked and cracked concrete

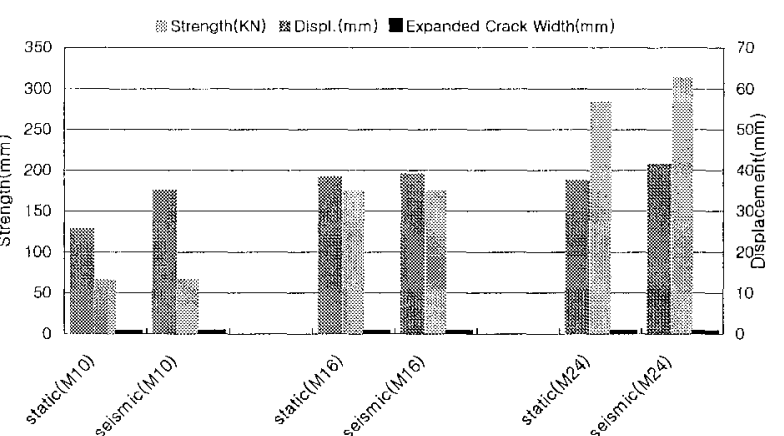

Figure 15 Comparison of static shear behavior with residual shear behavior after seismic shear tests in cracked concrete

II Strenoth(KN) $=$ Displ. $(\mathrm{mm})$ Expanded Crack Width $(\mathrm{mm})$

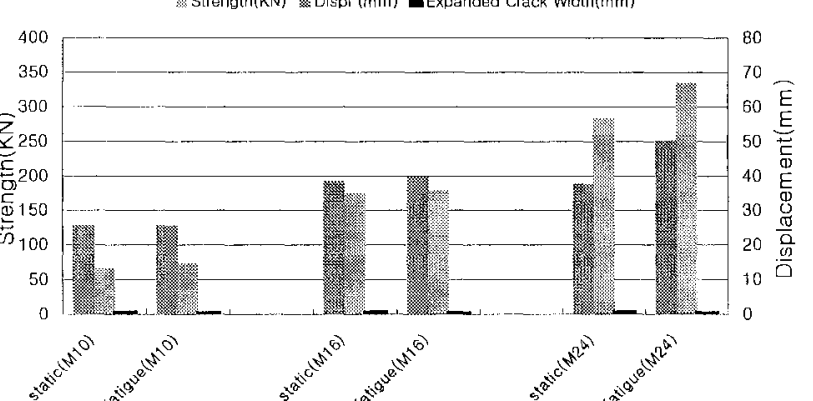

Figure 17 Comparison of static shear behavior with residual shear behavior after fatigue shear tests in cracked concrete

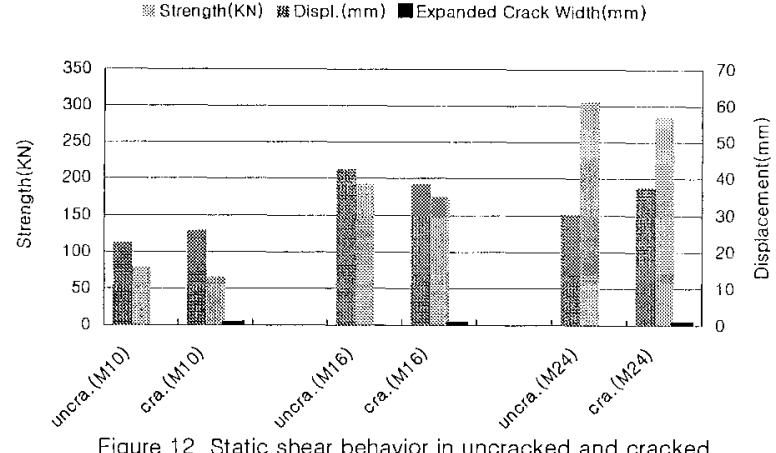

Figure 12 Static shear behavior in uncracked and cracked concrete

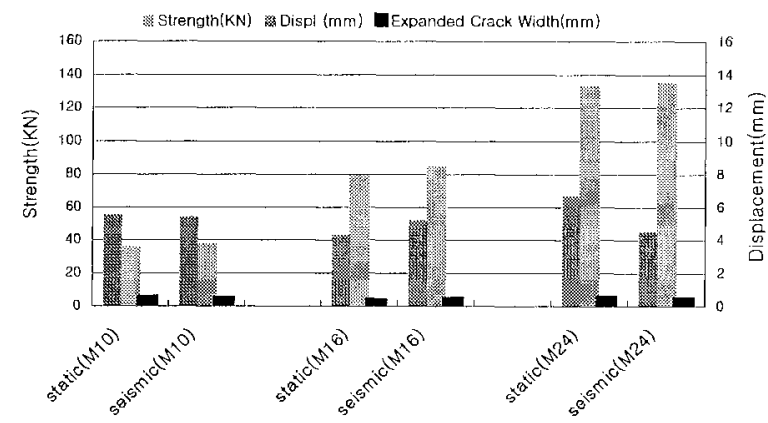

Figure 14 Comparison of static tensile behavior with residual tensile behavior after seismic tensile tests in cracked concete

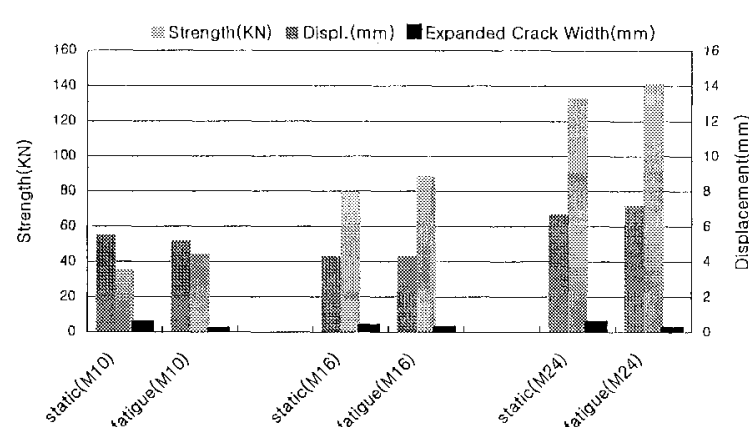

Figure 16 Comparison of static tensile behavior with residual tensile behavior after fatigue tensile tests in cracked concrete

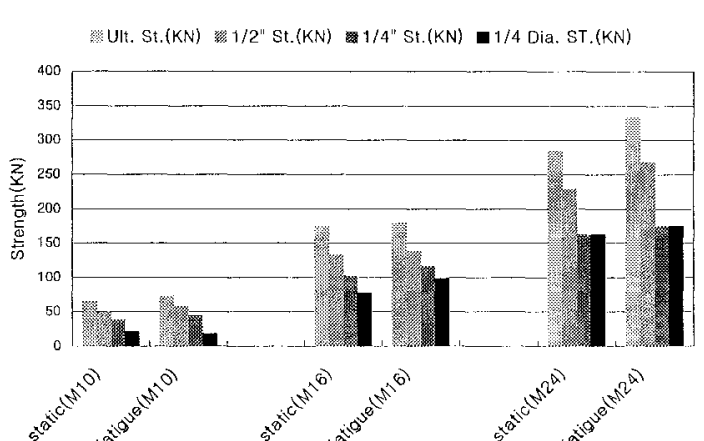

Figure 18 Comparison of static displacement based shear strength with residual shear strength after fatigue shear tests in cracked concrete 